\title{
Outcome of cephalo-medullary nailing in intertrochanteric fracture of femur
}

\author{
Sah Rabins Kumar*, Gupta Gaurav
}

Department of Orthopaedics and Traumatology, National Medical College and Teaching Hospital, Birgunj, Nepal

Received: 11 January 2022

Revised: 31 January 2022

Accepted: 01 February 2022

\section{*Correspondence:}

Dr. Sah Rabins Kumar,

E-mail: robins.shah@gmail.com

Copyright: () the author(s), publisher and licensee Medip Academy. This is an open-access article distributed under the terms of the Creative Commons Attribution Non-Commercial License, which permits unrestricted non-commercial use, distribution, and reproduction in any medium, provided the original work is properly cited.

\section{ABSTRACT}

Background: Intertrochanteric fracture is commonly seen in elderly and osteoporotic bone due to trivial trauma and requires hospitalization. Nonoperative treatment leads to complications like bedsore, pneumonia and deep vein thrombosis. The introduction of cephalomedullary nailing has broadened its use in complex intertrochanteric fracture with least complications.

Methods: A prospective observational study was conducted in Birgunj, Nepal from $4^{\text {th }}$ October 2020 to $3^{\text {rd }}$ October 2021 among 50 patients of age more than 30 years with closed intertrochanteric fractures. Ethical approval was obtained from the institutional review committee and proper informed consent was taken. Modified Harris hip scoring system was used. Type of implant used was PFN long and short.

Results: The mean age of 50 patients was 66.42 years, female to male ratio was 1.5:1 (30:20) and right side (72\%) with fall injury (78\%) was commonly observed. According to Kyles classification, $40 \%$ patients had Kyles's type II fracture followed by type III (38\%). Most of the cases start mobilization on $2^{\text {nd }}$ post operative day. Mean Harris hip score at 14 days, 6 weeks, 3 months and 6 months were 52.02, 64.50, 72.91 and 84.40 respectively. Early mobilization within 2 days of post-surgery had significant improvement in functional outcome throughout follow up as compared to more than 2 days ( $\mathrm{p}=0.001,0.001,0.001$ and 0.001 at 14 days, 6 weeks, 3 months and 6 months respectively). Radiological union was achieved in all cases within 6 months.

Conclusions: The study results concluded cephalomedullary nailing is effective treatment for intertrochanteric fracture.

Keywords: Cephalomedullary nail, Intertrochanteric fracture, Femur, Modified Harris hip score

\section{INTRODUCTION}

Intertrochanteric fracture is one of the most common fractures of the hip especially in the elderly with osteoporotic bones, usually due to low-energy trauma like simple falls. ${ }^{1}$ More than $90 \%$ of hip fractures in elderly are intertrochanteric fractures with complication rate of $20-30 \%$ and mortality rate of about $17 \% .^{2-4}$ Traditionally in early $19^{\text {th }}$ century, Intertrochanteric fracture treated with prolong continuous traction in skeletal traction. Long term immobilization on traction resulted in bed ridden for many days and suffer from psychosocial problems. ${ }^{5}$ Due to such complication, management of intertrochanteric fracture with skeletal traction, surgical treatment represents the optimal strategy. It allows early rehabilitation and functional recovery, and reduces the risk of post-operative complications. ${ }^{4}$

Surgical treatment includes, external fixation and internal fixations. ${ }^{6}$ Internal fixation is a most common surgical treatment for intertrochanteric fractures and intramedually (nails) and extra-medually (screws or plates) fixations are two commonly used approaches., ${ }^{78}$ Extramedullary fixation i.e. Dynamic compression plate and screw required large dissection while applying and blood loss is maximum. ${ }^{8-10}$ DHS does not show good 
outcome in Unstable Intertrochanteric fracture. ${ }^{9-11}$ To overcome this problems in surgical management of Intertrochanteric fracture of femur in old age, intramedullary fixation is come into practice. ${ }^{8-11}$ In Intertrochanteric fracture of femur the aim of treatment is to stabilize the fracture, control the rotational alignment, early mobilization, decrease morbidity and mortality, minimal incision, reduced wound infection, and decreased femoral neck shortening. ${ }^{10-12}$

AO/ASIF in 1996 designed a new medullary device, the "Cephalomedullary nail". ${ }^{13,14} \mathrm{CMN}$ has additional anti rotational screw (Hip pin), secondly nail tip is specially shaped to reduce the stress and therefore to prevent low energy fracture at the tip of the implant. ${ }^{14}$ Compared with DHS, CMN greatly reduces the lever arm distance from the reactionary forces generated in hip joint as a result of movements at the hip joint and increases compressive forces implanted to the tension side application of DHS. ${ }^{13}$ Rapid in implant and instrumentation in quest of an ideal fixation has made cephalomedullary nail superior. ${ }^{14}$ Less exposure time less soft tissue discretion less radiation exposure, less blood loss and most important is taking advantage of the natural biomechanics at the hip joint. ${ }^{13,14}$

\section{General objectives}

The objective of the study was to assess functional outcome of cephalomedullary nailing in intertrochanteric fracture of femur.

\section{Specific objectives}

The objective of the study was to assess the outcome by modified Harris hip score and to evaluate the mean time of radiological union.

\section{METHODS}

A prospective observational study was conducted in department of orthopedic surgery, National medical college and teaching hospital, Birgunj, Nepal from $4^{\text {th }}$ October 2020 to $3^{\text {rd }}$ October 2021, among 50 patients. Sample size was calculated using the formula $n=Z^{2} \times p(1-$ $\mathrm{p}) / \mathrm{m}^{2}$ and estimated prevalence of intertrochanteric fracture of femur in previous year in this institute was $\mathrm{p}=0.032(3.2 \%)$. Purposive sampling technique was used. Patients with age above 30 years, both sexes, closed intertrochanteric fracture of femur, patient fit for surgical procedure and who gave consent for study was included. Patients with cognitive disorder, age less than 30 years, associated with head injury, contralateral limb fracture, preexisting hip pathology like arthritis, patients not willing and medically not fit for surgical procedure was excluded from study. Ethical approval was obtained from the institutional review committee (IRC). Proper informed consent was taken from those patients who were fit for surgery and gave written consent. The fracture was classified according to Kyle's classification. The patients were treated with cephalomedullary nailing on standard fracture table under fluoroscopy and followed up at 2 weeks, 6 weeks, 3 months and 6 months till the radiological union was achieved. Modified Harris hip scoring system was used to assess the final outcome of the study. All data were processed, analyzed, and disseminated by MS office and statistical package for social sciences (SPSS) version 26

\section{RESULTS}

In this study, out of 50 patients, majority of the patients 30 $(60 \%)$ were female whereas $20(40 \%)$ were male and most of the patients 17 (34\%) were of age group 61-70 years.

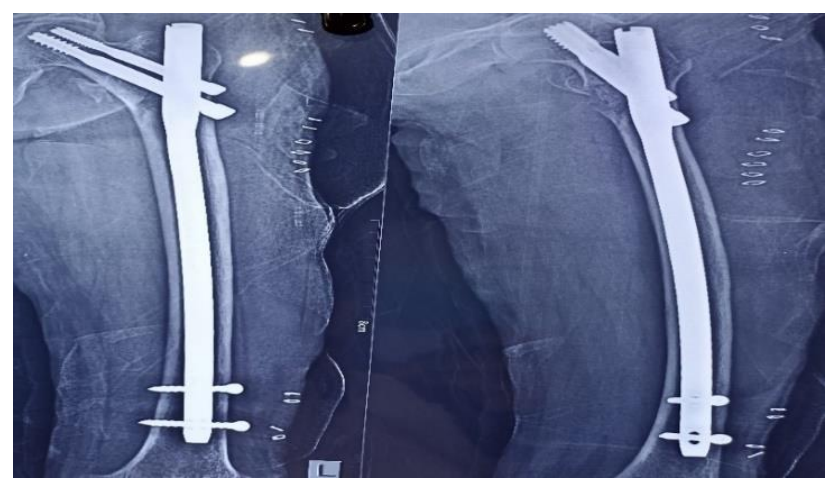

Figure 1: X-ray.

Table 1: Age distribution of the study participants, $(\mathbf{n}=\mathbf{5 0})$.

\begin{tabular}{|lll|}
\hline Age (years) & Frequency & Percentage $(\%)$ \\
\hline $\mathbf{3 0 - 4 0}$ & 3 & 6 \\
\hline $\mathbf{4 1 - 5 0}$ & 4 & 8 \\
\hline $\mathbf{5 1 - 6 0}$ & 11 & 22 \\
\hline $\mathbf{6 1 - 7 0}$ & 17 & 34 \\
\hline $\mathbf{7 1 - 8 0}$ & 8 & 16 \\
\hline $\mathbf{8 1 - 9 0}$ & 7 & 14 \\
\hline
\end{tabular}

The study result revealed $39(78 \%)$ patients sustained injury due to fall injury while $11(22 \%)$ patients due to road traffic accident (RTA) and $36(72 \%)$ patients had fracture on the right side while $14(28 \%)$ patients on left side. Regarding status of fracture stability, unstable fracture were $26(52 \%)$ and stable fracture $24(48 \%)$.

Intertrochanteric fracture was classified according to most commonly used Kyles classification system for intertrochanteric fracture

Table 2: Kyles classification of intertrochanteric fracture.

\begin{tabular}{|lll|}
\hline Type of fracture & Frequency & Percentage $(\%)$ \\
\hline Type 1 & 4 & 8 \\
\hline Type 2 & 20 & 40 \\
\hline Type 3 & 19 & 38 \\
\hline Type 4 & 7 & 14 \\
\hline Total & 50 & 100 \\
\hline
\end{tabular}


Out of 50 patients we found $11(22 \%)$ patients were suffering from cardiovascular disease while $10(20 \%)$ patients were suffering from chronic lung disease, $8(16 \%)$ patients had diabetes mellitus, $3(6 \%)$ had hypothyroidism and other $4(8 \%)$ were having renal disease, hepatobiliary disease, cerebral disease (stroke) and $13(26 \%)$ had no comorbidities. Among 50 patients, 6 (12\%) were operated in less than 24 hours from the time of injury, $15(30 \%)$ cases were operated between 24-48 hours, 12 (24\%) were operated in 48-72 hours and 17 (34\%) cases were operated in $>72$ hours. Time taken for surgery varied from 30 minutes to 180 minutes with mean time of 87.28 minutes and standard deviation of 30.494 . The $28(56 \%)$ case were operated within $61-90$ minutes followed by $9(18 \%)$ within 30-69 minutes, 8 (16\%) within 91-120 minutes, 4 (8\%) in 121-150 minutes and 1 case were in 151-180 minutes. In most of the patient, $18(36 \%)$ cases had blood loss about average of 100-200 ml, $16(32 \%)$ cases had 50-100 ml, 10 $(20 \%)$ cases had 200-300 $\mathrm{ml}$ and in $6(12 \%)$ had $>300 \mathrm{ml}$. Blood loss was measured by no. of soaked gauze pad and suction in drain and number of normal saline used to wash.

Mobilization was started on partial weight bearing and crutch walking as soon as possible after surgery. In 32 $(64 \%)$ cases mobilization was started from $2^{\text {nd }}$ postoperative day, followed by $16(32 \%)$ on $3^{\text {rd }}-7^{\text {th }}$ post- operative day. In 1 case mobilization was only possible after 6 weeks as he developed intraoperative complication and wound infection. In 1 case mobilization was not possible as he developed left ventricular failure and died on $3^{\text {rd }}$ post-operative day. In majority of the patients 47 (94\%) patients were allowed to full weight bear on 6 weeks of follow up. One (2\%) case was allowed weight bear after 3 months (12 weeks) as he developed wound infection and intraoperative fracture. In 2 cases mobilization was not possible as 1 developed left ventricular failure and died on $3^{\text {rd }}$ post-operative day and another died due to renal failure on $24^{\text {th }}$ post-op day. The study results showed that the mean duration of hospital stay was 11.18 days and standard deviation of 8.017.

The mean modified Harris hip score at 14 days, 6 weeks, 3 months and 6 months postoperatively were $52.02 \pm 6.01$, $64.50 \pm 6.15,72.91 \pm 7.86$ and $84.40 \pm 8.75$ respectively.

There was a significant relationship between early mobilization and improvement in Harris hip score at the time of discharge, at 14 days, 6 weeks, 3 months and 6 months post-surgery with $\mathrm{p}=0.001,0.001,0.001$ and 0.001 respectively.

Table 3: Distribution of patients with modified Harris hip score.

\begin{tabular}{|c|c|c|c|c|c|c|c|c|}
\hline \multirow{3}{*}{ Variables } & \multicolumn{8}{|c|}{ Modified Harris hip score } \\
\hline & \multicolumn{2}{|c|}{14 Days } & \multicolumn{2}{|c|}{6 Weeks } & \multicolumn{2}{|c|}{3 Months } & \multicolumn{2}{|c|}{6 Months } \\
\hline & $\mathbf{N}$ & $\%$ & $\mathbf{N}$ & $\%$ & $\mathbf{N}$ & $\%$ & $\mathbf{N}$ & $\%$ \\
\hline$<70$ (poor) & 49 & 98 & 37 & 74 & 16 & 32 & 3 & 6 \\
\hline $71-79$ (fair) & - & - & 11 & 22 & 17 & 34 & 10 & 20 \\
\hline 81-89 (good) & - & - & - & - & 13 & 26 & 17 & 34 \\
\hline 90-100 (excellent) & - & - & - & - & - & - & 13 & 26 \\
\hline Missing case (dead) & 1 & 2 & 2 & 4 & 4 & 8 & 7 & 14 \\
\hline Total & 50 & 100 & 50 & 100 & 50 & 100 & 50 & 100 \\
\hline
\end{tabular}

Table 4: Day of mobilization started and modified Harris hip score.

\begin{tabular}{|c|c|c|c|c|c|c|}
\hline Variables & Days in mobilization (days) & $\mathbf{N}$ & Mean & SD & $\mathbf{T}$ & $\mathbf{P}$ \\
\hline \multirow{2}{*}{$\begin{array}{l}\text { Modified Harris hip } \\
\text { score-14 days }\end{array}$} & $<2$ & 32 & 54.31 & 5.515 & \multirow{2}{*}{4.275} & \multirow{2}{*}{$<0.001$} \\
\hline & $\geq 3$ & 17 & 47.71 & 4.356 & & \\
\hline \multirow{2}{*}{$\begin{array}{l}\text { Modified Harris hip } \\
\text { score- } 6 \text { weeks }\end{array}$} & $<2$ & 32 & 67.19 & 4.540 & \multirow{2}{*}{5.423} & \multirow{2}{*}{$<0.001$} \\
\hline & $\geq 3$ & 16 & 59.13 & 5.451 & & \\
\hline \multirow{2}{*}{$\begin{array}{l}\text { Modified Harris hip } \\
\text { score-3 months }\end{array}$} & $<2$ & 31 & 76.77 & 5.789 & \multirow{2}{*}{6.761} & \multirow{2}{*}{$<0.001$} \\
\hline & $\geq 3$ & 15 & 64.93 & 5.063 & & \\
\hline \multirow{2}{*}{$\begin{array}{l}\text { Modified Harris hip } \\
\text { score-6 months }\end{array}$} & $<2$ & 30 & 89.13 & 4.083 & \multirow{2}{*}{9.611} & \multirow{2}{*}{$<0.001$} \\
\hline & $\geq 3$ & 13 & 73.46 & 6.489 & & \\
\hline
\end{tabular}

In all cases, fracture union was achieved by 6 months. Zeffect was seen in $1(2 \%)$ case at 3 months follow up. Reverse Z-effect were seen in $2(4 \%)$ cases, 1 at 3 months and 1 at 6 months follow up

\section{DISCUSSION}

In our study, 50 patients were included with mean age of 66.42 years ( 30 years to 90 years) and most were age group
(61-70 years). In a study done by Korkmaz et al mean age of the patients was 77.66 years (range: $37-98$ years) and in study of Li et al showed the mean age of patients was 74.7 years and similarly Gadegone et al showed in their study the mean age was 67 (56-83) years, which was similar to our study. ${ }^{15-17}$ In our study, out of 50 patients $30(60 \%)$ were female and 20(40\%) were male. The demographics were similar to study results of Korkmaz et al in which the sex distribution was 32 males and 68 females. ${ }^{15}$ 
The study result revealed $39(78 \%)$ cases sustained injury due to fall and $11(22 \%)$ cases due to road traffic accident (RTA). Fall injury included like fall while walking, fall from bed, and fall from height. Our study was similar to Li et al which showed sustained injury by domestic fall in 117 cases and RTA in 46 cases. ${ }^{16}$ Korkmaz et al revealed in their study that mechanisms of injury were simple fall at home 87 , simple fall outside home 4 , traffic accident 4 , sports injury 3 and Gunshot $1 .{ }^{15}$ In our study, 24 (48\%) were stable fracture and $26(52 \%)$ were unstable. Study conducted by Gadegone et al showed $36(36 \%)$ cases had stable fracture and $64(64 \%)$ had unstable facture. ${ }^{17}$

The mean time interval from injury to surgery were 3.00 days (range 1 to 7 days). Among 50 patients, 17 (34\%) cases were operated in $>72$ hours $15(30 \%)$ cases were operated between 24-48 hours from the time of injury, 12 (24\%) were operated in 48-72 hours and 6 (12\%) were operated in less than 24 hours. According to Novack et al patients who had surgery within 2 days had lower mortality (in hospital, 1 month, and 1 year) compared to those who waited for surgery more than 4 days but the author has not mentioned about the functional recovery in subsequent follow up. ${ }^{18}$ In our study, operative delay was prolonged due to comorbidities and hence longer period of pre operative optimization for surgery.

Time taken for surgery varied from 30 minutes to 180 minutes with mean time of 87.28 minutes and standard deviation of 30.49 . The $28(56 \%)$ case were operated within 61-90 minutes followed by $9(18 \%)$ within $30-60$ minutes, 8 (16\%) within 91-120 minutes, 4 (8\%) in 121150 minutes and 1 case in 151-180 minutes. The average duration of surgery was slightly less i.e., $45.7 \mathrm{~min}$ (range, $35-110 \mathrm{~min}$ ) in the study conducted by $\mathrm{Li}$ et al. ${ }^{16}$ In the study of Korkmaz et al the mean duration of the operation was 87.9 minutes (range: $30-300$ minutes). ${ }^{15}$

Out of 50 patients, $18(36 \%)$ cases had blood loss in an about average of 100-200 ml, $16(32 \%)$ cases had 50-100 $\mathrm{ml}, 10(20 \%)$ cases had $200-300 \mathrm{ml}$ and in $6(12 \%)$ had $>300 \mathrm{ml}$. Blood loss was measured by number of soaked gauze pad and suction in drain and number of normal salines used to washed. Our study was supported by Li et al study, in which average intra-operative blood loss of $115.2 \mathrm{ml}$ (range, $65-430 \mathrm{ml}$ ). ${ }^{16}$ Kale et al study showed the mean blood loss $87.17 \pm 27.84 \mathrm{ml}$ in long PFN group and 98.67 $\pm 47.32 \mathrm{ml}$ in short PFN group. ${ }^{19} \mathrm{Li}$ et al, Kale et al and our study showed less blood loss due to minimum incision and short operation duration. ${ }^{16,19}$

Mobilization was started on partial weight bearing and crutch walking as soon as possible after surgery. In 32 $(64 \%)$ cases mobilization was started from $2^{\text {nd }}$ postoperative day, followed by $16(32 \%)$ on $3^{\text {rd }}-7^{\text {th }}$ postoperative day. In 1 case mobilization was only possible after 6 weeks as he developed intraoperative complication and wound infection. FWBCW was started after 6 weeks in $47(94 \%)$ cases and $1(2 \%)$ cases were started after 12 weeks as he developed wound infection. Study conducted by Boldin et $\mathrm{al}^{20}$ showed immediate full weight bearing was permitted in 49 cases and partial weight bearing in 6 cases. Study conducted by Kawatani et al showed all cases were allowed weight bear from the $1^{\text {st }}$ post operative day. ${ }^{21}$ In our study, significant association was found between mobilization started within 2 days of post-surgery and improvement in Harris hip score at the time of discharge, 14 days, 6 weeks, 3 months and 6 months post-surgery with $\mathrm{p}=0.001,0.001,0.001,0.001$, respectively as compared to mobilization started after 2 days. Study results of Sui et al showed in patients with hip fractures delay in getting the patients out of bed was associated with poor outcome at 2 months and worsened 6 months survival. ${ }^{22}$ Many authors revealed in their study that early mobilization results into better functional outcome. ${ }^{17,22,23}$

Functional outcome classified as per modified Harris hip score was excellent in 13 patients (26\%), good in 17 patients $(34 \%)$, fair in 10 patients $(20 \%)$ and poor 3 patients $(6 \%)$ on 6 months follow up. Asad et al showed in their study that excellent outcome observed in $28.6 \%$ patients, good in $45.1 \%$, fair outcome in $16.5 \%$ and only $9.9 \%$ expressed poor outcome among 91 patients. $^{24}$ Similar results were shown by Uzun et al in their study, were excellent in $11(31.4 \%)$ patients, good in $15(42.9 \%)$ and fair in 7 (20\%) patients. ${ }^{25}$ Most author revealed that intertrochanteric facture of femur treated with CMN has excellent outcome as per modified Harris hip score. ${ }^{16,17,23-25}$

In our study, out of 50 patients, $4(8 \%)$ patients had thigh pain, $2(4 \%)$ had reverse Z-effect and $1(2 \%)$ had Z-effect. They had pain on weight bearing and limitation in mobilization in subsequent follow up. There was wound infection $1(2 \%)$ case. Similar result was found by Kawatani et al. ${ }^{21}$ Six cases $(1.7 \%)$ included where wound infection in two cases, and one case each with secondary fracture at subtrochanteric region, nonunion, back-out of the guiding sleeve and medial perforation of the lag screw. Gadegone et al found two patients had Z-effect and one reverse Z-effect. ${ }^{17}$

In all cases, fracture union was achieved by 6 months. Our study was supported by Yadkikar et al study in which they found average fracture union time was 16 weeks and Rethnam et al study in which fracture union time was 14.8 \pm 3.76 weeks (Range: $8-24$ weeks). ${ }^{26,27}$

\section{Limitation}

The limitations were-small sample size. Long term follows up required for functional outcome for more authenticity and validity.

\section{CONCLUSION}

Cephalo-medullary nailing is effective treatment for stable and unstable intertrochanteric fracture of femur. It provides stable fixation and early mobilization. 


\section{Recommendations}

It is to recommend for conducting more studies regarding the same issue with larger sized sample.

Funding: No funding sources Conflict of interest: None declared

Ethical approval: The study was approved by the institutional ethics committee

\section{REFERENCES}

1. Dimon JH, Hughston JC. Unstable intertrochanteric fractures of the hip. J Bone Joint Surg Am. 1967;49(3):440-50.

2. Campbell WC, Canale ST, Beaty JH. Campbell's operative orthopaedics. $14^{\text {th }}$ ed. Philadelphia, PA: Mosby/Elsevier. 2020.

3. Rockwood CA, Green DP, Bucholz RW. Rockwood and Green's fractures in adults. $9^{\text {th }}$ ed. Philadelphia, PA: Wolters Kluwer Health/Lippincott Williams and Wilkins. 2019.

4. Kenzora JE, Mccarthy RE, Lowell JD, Sledge CB. Hip fracture mortality. Relation to age, treatment, preoperative illness, time of surgery, and complications. Clin Orthop Related Res. 1984(186):45-56.

5. Mao-qi G, Yu-jiang M, Jie W, Man-Yi W, Jie B, Qiao-ling $\mathrm{F}$ et al. Outcome of hip fractures after traction treatment in elderly. Zhonghua Yi Xue Za Zhi. 2005;85(46):3263-5.

6. Magyar G, Toksvig-Larsen S, Moroni A. Hydroxyapatite coating of threaded pins enhances fixation. J Bone Joint Surg Br. 1997;79(3):487-9.

7. Miyamoto RG, Kaplan KM, Levine BR, Egol KA, Zuckerman JD. Surgical management of hip fractures: an evidence-based review of the literature. I: femoral neck fractures. J Am Academy Orthop Surg. 2008;16(10):596-607.

8. Fung $\mathrm{W}$, Jönsson $\mathrm{A}$, Bühren $\mathrm{V}$, Bhandari $\mathrm{M}$. Classifying intertrochanteric fractures of the proximal femur: does experience matter? Med Principles Practice. 2007;16(3):198-202.

9. Kaplan K, Miyamoto R, Levine BR, Egol KA, Zuckerman JD. Surgical management of hip fractures: an evidence-based review of the literature. II: intertrochanteric fractures. J Am Academy Orthop Surg. 2008;16(11):665-73.

10. Morris AH, Zuckerman JD, American Academy of Orthopaedic Surgeons Council of Health Policy and Practice. National Consensus Conference on Improving the Continuum of Care for Patients with Hip Fracture. J Bone Joint Surg Am. 2002;84:670-4.

11. Jonnes C, Shishir S, Najimudeen S. Type II intertrochanteric fractures: proximal femoral nailing (PFN) versus dynamic hip screw (DHS). Arch Bone Joint Surg. 2016;4(1):23.

12. Wu Y, Watson JT, Kuldjanov D, Jackman J. Rotationally stable fixation for intertrochanteric hip fractures: the Intertan experience, surgical technique, and outcomes. Tech Orthop. 2014;29(3):120-32.

13. Gadegone Wasudeo M, Salphale Yogesh S. Short proximal femoral nail fixation for trochanteric fractures. J Orthop Surg. 2010;18(1):39-44.

14. Terry Canale S, James H Beaty, Campbell's Operative orthopaedics, Elsevier, $13^{\text {th }}$ edition. 2017;3239.

15. Korkmaz MF, Erdem MN, Disli Z, Selcuk EB, Karakaplan M, Gogus A. Outcomes of trochanteric femoral fractures treated with proximal femoral nail: an analysis of 100 consecutive cases. Clin Interventions aging. 2014;9:569.

16. Li M, Wu L, Liu Y, Wang C. Clinical evaluation of the Asian proximal femur intramedullary nail antirotation system (PFNA-II) for treatment of intertrochanteric fractures. J Orthop Surg Res. 2014;9(1):112.

17. Gadegone WM, Salphale YS. Short proximal femoral nail fixation for trochanteric fractures. J Orthop Surg. 2010;18(1):39-44.

18. Novack V, Jotkowitz A, Etzion O, Porath AV. Does delay in surgery after hip fracture lead to worse outcomes? A multicenter survey. Int J Quality Health Care. 2007;19(3):170-6.

19. Kale A, Munde D, Mangukiya HJ, Waghmare V. A comparative study of long versus short proximal femoral nail in peritrochanteric and subtrochanteric fractures in adults. Int J Orthop. 2018;4(2):717-21.

20. Boldin C, Seibert FJ, Fankhauser F, Peicha G, Grechenig W, Szyszkowitz R. The proximal femoral nail (PFN)-a minimal invasive treatment of unstable proximal femoral fractures: a prospective study of 55 patients with a follow-up of 15 months. Acta Orthopaedica Scandinavica. 2003;74(1):53-8.

21. Kawatani Y, Nishida K, Anraku Y, Kunitake K, Tsutsumi Y. Clinical results of trochanteric fractures treated with the TARGON® proximal femur intramedullary nailing fixation system. Injury. 2011;42:S22-7.

22. Sui AL, Penrod JD, Boockvar KS, Koval K, Strauss E, Morrison RS. Early ambulation after hip fracture. Arch Intern Med. 2006;166:766-71.

23. Vishwanathan K, Akbari K, Patel AJ. Is the modified Harris hip score valid and responsive instrument for outcome assessment in the Indian population with pertrochanteric fractures? J Orthop. 2018;15(1):40-6.

24. Asad KG, Syed KAS, Muhammad AK, Muhammad AG, Muhammad KRN. Role of Proximal Femoral Nail in the Treatment of Unstable Intertrochanteric Fractures. Biomed J Sci Tech Res. 2018;2(1):000645.

25. Uzun M, Ertürer E, Ozturk I, Akman S, Seçkin F. Longterm radiographic complications following treatment of unstable intertrochanteric femoral fractures with the proximal femoral nail and effects on functional results. Acta Orthop Traumatol Turc. 2009;43(6):457-63.

26. Yadkikar S, Yadkikar V, Prasad D, Marawar A. Prospective study of proximal femoral nail in management of trochanteric and subtrochanteric 
fractures of femur. Int $\mathbf{J}$ Biomed Adv Res. 2015;6(4):349-54.

27. Rethnam U, Cordell-Smith J, Kumar TM, Sinha A. Complex proximal femoral fractures in the elderly managed by reconstruction nailing-complications and outcomes: a retrospective analysis. J Trauma Management Outcomes. 2007;1(1):7.
Cite this article as: Kumar SR, Gaurav G. Outcome of cephalo-medullary nailing in intertrochanteric fracture of femur. Int J Res Orthop 2022;8:132-7. 